This is the post-print version of the article Q. Chen, Q. Shi, S. Signetti, F. Sun, Z. Li, F. Zhu, S. He, N.M. Pugno. Plastic collapse of cylindrical shell-plate periodic honeycombs under uniaxial compression: experimental and numerical analyses. Int. J. Mech. Sci. 111-112:125-133, 2016 available in its final version at the following URL: http://dx.doi.org/10.1016/j.ijmecsci.2016.03.020

\title{
Plastic collapse of cylindrical shell-plate periodic honeycombs under uniaxial compression: experimental and numerical analyses
}

Qiang Chen a, ${ }^{\mathrm{a}}$, Quan Shi ${ }^{\mathrm{a}}$, Stefano Signetti ${ }^{\mathrm{b}}$, Fangfang Sun ${ }^{\mathrm{c}}$, Zhiyong $\mathrm{Li}^{\mathrm{a}}$, Feipeng Zhu ${ }^{\mathrm{c}}$, Siyuan $\mathrm{He}^{\mathrm{a}}$, Nicola M. Pugno ${ }^{\mathrm{b}, \mathrm{d}, \mathrm{e}, * *}$

${ }^{a}$ Biomechanics Laboratory, School of Biological Science and Medical Engineering, Southeast University, 210096 Nanjing, PR China

${ }^{b}$ Laboratory of Bio-Inspired and Graphene Nanomechanics, Department of Civil, Environmental and Mechanical Engineering, University of Trento, via Mesiano 77, I-38123 Trento, Italy

${ }^{c}$ School of Mechanics and Materials, Hohai University, Nanjing 210098, PR China

${ }^{d}$ Centre for Materials and Microsystems, Fondazione Bruno Kessler, via Sommarive 18, I-38123 Povo (Trento), Italy

${ }^{e}$ School of Engineering and Materials Science, Queen Mary University of London, Mile End Road, E14NS London, UK

*Corresponding author at: Biomechanics Laboratory, School of Biological Science and Medical Engineering, Southeast University, 210096 Nanjing, PR China - e-mail: chen999@gmail.com

**Corresponding author at: Laboratory of Bio-Inspired and Graphene Nanomechanics, Department of Civil, Environmental and Mechanical Engineering, University of Trento, via Mesiano 77, I-38123 Trento, Italy - e-mail: nicola.pugno@unitn.it

\begin{abstract}
This paper studies the plastic collapse mechanisms of uniaxially-loaded cylindrical shell-plate periodic honeycombs with identical mass (or relative density) but varying geometric parameters, by series of in-plane and out-of-plane experiments and finite element numerical simulations. The coupled experimental-numerical results show that mechanical properties of the honeycomb can be optimized in all three loading cases, thanks to the complementary changes of the mechanical properties of cylindrical shell and plate as the geometric parameters vary. The work presents a concept to optimize lattice structures by combining different substructures, and can be used in designing new low-density honeycomb structures with desired mechanical requirements but less base materials and weight.
\end{abstract}

\section{Keywords}

Cylindrical shell-plate honeycomb; Low-density honeycomb structure; Finite element analysis; Plastic collapse 
This is the post-print version of the article Q. Chen, Q. Shi, S. Signetti, F. Sun, Z. Li, F. Zhu, S. He, N.M. Pugno. Plastic collapse of cylindrical shell-plate periodic honeycombs under uniaxial compression: experimental and numerical analyses. Int. J. Mech. Sci. 111-112:125-133, 2016 available in its final version at the following URL: http://dx.doi.org/10.1016/j.ijmecsci.2016.03.020

\section{Introduction}

Honeycomb and foamy structures widely exist in natural materials (e.g., Luffa sponge [1]), which are shaped by their surrounding environment. In view of optimization in the process of natural evolution, it facilitates the study of the natural or man-made foamy materials with multiple functions, such as energy-absorption [2], heat-transfer [3,4] and electromagnetic absorption [5]. To date, varieties of honeycomb structures are presented. From the point of view of mechanics, the conventional hexagon, square, triangle, Kagome honeycombs [6] or 3D topological lattices [7] have been widely studied, and their collapse mechanisms clearly described [8-10]. These studies have already been used as guidance for the design of porous materials.

As the importance of hierarchical strategy in natural materials is gradually realized, hierarchical honeycomb and foamy structures are also constructed and studied. In general, as the porosity of the structure increases, reducing the relative density of the structure, their mechanical properties decrease (e.g., critical buckling load [11]). However, if a hierarchical structure is designed with a constant amount of bulk materials, its mechanical properties, such as Young's modulus and strength [12], can be optimized by replacing solid cell walls [13], $[14,15]$ or joints $[16,17]$ of conventional single-level honeycombs with porous substructures. In the case of the solid cell walls replaced by porous substructures, the bending rigidity of the cell walls is increased because of the increased porous cell-wall thickness $[12,18]$, and in the other case, i.e., joints replaced by porous substructures, the failure modes of the cell walls and porous joints are interchanged [19]. It is worth mentioning that when the hierarchical level comes down into the nanoscale, the surfaces effect has to be taken into account $[20,21]$.

To look for new and more efficient honeycomb structures, very recently, the authors presented a cylindrical shell-plate assembled periodic (or so-called hollow-cylindrical-joint) honeycomb (Fig. 1) [19], which actually derives from the family of center-symmetrical honeycombs [22], and analytically studied its Young's modulus, Poisson's ratio, fracture strength and toughness in the $x$ direction. Moreover, they reported that the mechanical properties of the structure were optimized and improved compared to the conventional hexagonal honeycombs, thanks to the variation of structural styles. But the work only dealt with the in-plane mechanical properties in the $x$ direction via a theoretical approach [19]. Then, questions rise: what about the in-plane mechanical properties in the $y$ direction and out-of-plane mechanical properties? Are they also optimized? 
This is the post-print version of the article Q. Chen, Q. Shi, S. Signetti, F. Sun, Z. Li, F. Zhu, S. He, N.M. Pugno. Plastic collapse of cylindrical shell-plate periodic honeycombs under uniaxial compression: experimental and numerical analyses. Int. J. Mech. Sci. 111-112:125-133, 2016 available in its final version at the following URL: http://dx.doi.org/10.1016/j.ijmecsci.2016.03.020

In order to thoroughly describe the mechanical behaviours of the assembled periodic honeycomb, we here continued the study of the honeycomb by coupling experiments and numerical simulations. First, two sets of quasi-static crushing experiments (six in-plane samples with eight unit cells loaded in the $x, y$ directions, Fig. 1a, and five out-of-plane samples with three unit cells in the $z$ direction, Fig. 1b) were performed. Plastic collapse processes of selected samples and stress-strain curves of all samples were recorded. Second, non-linear finite element method (FEM) numerical simulations were employed to deeply reveal plastic and fracture behaviours and stress states, which were not visually identifiable with the experiments. Finally, the collapse mechanisms were discussed.

\section{Introduction}

\subsection{Experiments}

Using 6061-T4 aluminum alloy as the bulk constituent material, eleven honeycomb samples with a controlled dimensional error $0.03 \mathrm{~mm}$ in thickness, were fabricated by Nanjing Siyou Photoelectric Technology Limited, Nanjing, China. In the design of the samples, the samples had theoretically identical relative density $\rho^{*} / \rho^{\mathrm{c}}=0.1$ in which $\rho^{*}=0.27 \mathrm{~g} / \mathrm{cm}^{3}$ and $\rho^{\mathrm{c}}=2.7 \mathrm{~g} / \mathrm{cm}^{3}$ are the densities of the honeycomb and the bulk aluminum alloy, respectively. The sizes in $z$ direction were $20 \mathrm{~mm}$ and $30 \mathrm{~mm}$ for the in-plane and out-of-plane samples, respectively, and the distance $l$ between centres of two adjacent cylindrical shells was fixed to be $20 \mathrm{~mm}$. The radius $r$ of the cylindrical shell was first selected, and the wall thickness $t$ was determined by the following equation $\rho^{*} / \rho^{c}=-1.155 \cdot(t / l)^{2}+[2.528 \cdot(r / l)+1.155] \cdot(t / l)[19]$, and the masses of the models were calculated by multiplying the volumes of the samples to their density $\rho^{*}=0.27$ $\mathrm{g} / \mathrm{cm}^{3}$, see Table 1 .

Actually, their real masses $m_{\mathrm{re}}$ are lower, see Table 1 . Moreover, according to the design, the masses of the in-plane samples should theoretically be equal, and also for the out-of-plane ones, here the mass difference is due to the samples' processing.

The samples were tested under uniaxial compression with a 1000HDX Instron Universal Testing Machine (ITW, USA) with loading capacity of $1000 \mathrm{kN}$. Before testing, in order to ensure the samples to be loaded uniformly, two steel plates were respectively placed at the top and bottom surfaces of the samples. The whole loading process was displacement controlled from the bottom up. For the in-plane samples, considering their larger size along the loading direction, a short linear-elastic stage of stress-strain curves and limit influence of loading rate 
This is the post-print version of the article Q. Chen, Q. Shi, S. Signetti, F. Sun, Z. Li, F. Zhu, S. He, N.M. Pugno. Plastic collapse of cylindrical shell-plate periodic honeycombs under uniaxial compression: experimental and numerical analyses. Int. J. Mech. Sci. 111-112:125-133, 2016 available in its final version at the following URL: http://dx.doi.org/10.1016/j.ijmecsci.2016.03.020

on the plastic collapse stage were expected; thus, the loading rates before and after the initial yield of the samples were set to be $1 \mathrm{~mm} / \mathrm{min}$ and $10 \mathrm{~mm} / \mathrm{min}$, respectively. For the out-ofplane samples, the loading rate was kept constant at $1 \mathrm{~mm} / \mathrm{min}$.

Regarding the definitions of stress and strain of the compressed honeycombs in the experiments, the stress was calculated as $\sigma=F / A$, in which $F$ was the applied load, and $A$ was the projected convex hull area of the honeycomb samples on the plane perpendicular to the loading direction; the strain was calculated as $\varepsilon=\Delta h / h_{0}$, where $\Delta h$ was the height variation, and $h_{0}$ was the initial height of the compressed samples.

For the numerical models, material properties and stress-strain relationship of the aluminum alloy used in the experiment were characterized by tensioning a dog-bone specimen with circular cross-section of diameter $d=10 \mathrm{~mm}$ up to failure (see the inset in Fig. 2). The mechanical properties extracted from the stress-strain curve (Fig. 2) were: Young's modulus $E=68 \mathrm{GPa}$, the yield strength $\sigma_{\mathrm{y}}=287 \mathrm{MPa}$, the peak stress $\sigma_{\mathrm{u}}=318 \mathrm{MPa}$, and the failure strain $\varepsilon_{f}=0.121$. These values are consistent with those in literature [23].

\subsection{Finite element models}

The aim of finite element simulations is to analyze the stress state of the honeycombs under compression loads, to visualize the plastic deformation, and to further to develop a referential tool for future mechanical analysis of other honeycombs.

The FEM model geometry was made up of honeycombs between two rigid steel plates. The honeycomb material was modeled with a piecewise elastic-plastic curve: the linear elastic stage was defined by the experimentally determined $\sigma_{\mathrm{y}}$ and $E$, while the plastic stage followed the actual experimental points (Fig. 2) in order to include the softening stage after the reach of the peak stress prior to failure. It is worth mentioning that due to the size-scale effect, the plastic strain $\varepsilon_{\mathrm{pl}, \mathrm{FEM}}$ and ultimate strain $\varepsilon_{\mathrm{u}, \mathrm{FEM}}$ in the FEM models were both scaled from the nominal one $\varepsilon_{\mathrm{pl}}$ measured from the dog-bone test by $\varepsilon_{\mathrm{pl}, \mathrm{FEM}} / \varepsilon_{\mathrm{pl}}=d / t$, since $t \ll d$. This scaling was necessary, since by introducing the material law derived from dog-bone traction in the FEM material model we obtained brittle fracture at low strain, while with this scaling we were able to obtain comparable results with the experimental compression tests. Von-Mises criterion was employed for yielding. Contact interactions were taken into account between the steel plates and the honeycomb and self-contact within the honeycomb parts in the crushing process: static and dynamic coefficients of friction were respectively set to be $0.61 / 0.47$ for the honeycomb- 
This is the post-print version of the article Q. Chen, Q. Shi, S. Signetti, F. Sun, Z. Li, F. Zhu, S. He, N.M. Pugno. Plastic collapse of cylindrical shell-plate periodic honeycombs under uniaxial compression: experimental and numerical analyses. Int. J. Mech. Sci. 111-112:125-133, 2016 available in its final version at the following URL: http://dx.doi.org/10.1016/j.ijmecsci.2016.03.020

steel contact and 1.35/1.05 for the self-contact. For the in-plane and out-of-plane models, 4node fully integrated shell elements with $2 \times 2$ Gauss integration (4 integration points through thickness, element side-thickness aspect-ratio 2:1) and 8-node selective reduced integrated brick elements (3 elements in the wall thickness, aspect ratio 1:1:1) with volumetric locking alleviation were employed, respectively. The loading process was displacement controlled with the bottom one moved towards the top at the same prescribed velocities as the experiments reported above. The load $F$ carried by the honeycomb was computed from the resultant component along the loading axis of the contact forces at the steel plate-honeycomb interface. Material fracture was treated via an erosion algorithm: when all the integration points of an element reach the ultimate strain $\varepsilon_{\mathrm{u}, \mathrm{FEM}}$ (maximum principal strain), the element is deleted from simulation, and then fracture enucleate and propagate by progression of erosions.

\section{Results}

\subsection{In-plane mechanical behaviour}

The in-plane mechanical behaviour of the six honeycombs compressed in the $x$ and $y$ directions is plotted in Fig. 3. It can be seen that the stress-strain curves generally take on a serrated feature, due to the fracture in cylindrical shells and plates, and the linear-elastic stage (E1) of all samples is very short. The FEM results (dashed line) and experimental results (solid line) are in good agreement, both in terms of curve shape and of honeycomb bearing capacity. The samples 1 and $3(r / l=0.2$, red line and $r / l=0.4$, blue lines) have only one plateau stage, whereas, the sample 2 ( $r / l=0.3$, green line) has two linear-elastic or plateau stages (Fig. 3a and b), and the second linear-elastic (E2) and plateau (P2) stages are longer and much shorter than their first counterparts (i.e., E1 and P1), respectively. The sample 2 reaches densification earlier than the samples 1 and 3.

Young's moduli (the slope of linear-elastic stages, see the insets in Fig. 3a and b) of the honeycombs are optimized in both directions when $r / l=0.3$ for FEM and experimental results, but the values from FEM result are much larger than those from experiments, and this is consistent with the literature $[24,25]$. It is analyzed that the discrepancy is mainly due to the over-estimated strain, which was calculated by employing the cross-head displacement of the testing system instead of the real deformation of the samples. However, because this work studies the plastic collapse behaviour of the honeycomb, Young's modulus is not in the scope. 
This is the post-print version of the article Q. Chen, Q. Shi, S. Signetti, F. Sun, Z. Li, F. Zhu, S. He, N.M. Pugno. Plastic collapse of cylindrical shell-plate periodic honeycombs under uniaxial compression: experimental and numerical analyses. Int. J. Mech. Sci. 111-112:125-133, 2016 available in its final version at the following URL: http://dx.doi.org/10.1016/j.ijmecsci.2016.03.020

Yield strengths of the three samples in the $x$ direction are $1.11 \mathrm{MPa}(r / l=0.2), 1.20 \mathrm{MPa}$ $(r / l=0.3), 1.02 \mathrm{MPa}(r / l=0.4)$ for experiments $v s .1 .19 \mathrm{MPa}, 1.29 \mathrm{MPa}, 1.10 \mathrm{MPa}$ for FEM; in the $y$ direction, and they are $1.19 \mathrm{MPa}(r / l=0.2), 1.34 \mathrm{MPa}(r / l=0.3), 0.96 \mathrm{MPa}(r / l=0.4)$ for experiments vs. 1.28 MPa, 1.42 MPa, 1.10 MPa for FEM. Differently from the Young's modulus, FEM and experimental values are comparable since the stress in experiments calculated directly from the readout of the load cell, which reflects the real load sustained by the samples. From these data, we can see that the yield strengths are optimized when $r / l=0.3$, which is consistent with the previous work [19], and the finite element results are slightly greater than the experimental counterparts. Moreover, the yield strength in the $x$ direction is less than that in the $y$ direction, and this is caused by the different structures of the two directions, with the compressed samples in the $x$ direction including the extra axial deformation or instability of the vertical plates. Considering the effect of the mass variations among samples, we here also compare the yield strength to mass ratio, and again the optimal case for both directions corresponds to $r / l=0.3$ (Fig. $3 c$ and d). The coherent optimizations (yield strength and yield strength to mass ratio) are due to the little mass difference for each intra-group (i.e., two groups are $x$ and $y$ directions).

In addition, the large deformations and failure mechanisms (Fig. 4 and 5) in both directions are observed. For the $x$ direction, the samples 1 and 2 (i.e., $r / l=0.2,0.3$ ) have an approximate anti-symmetric configuration (Fig. $4 \mathrm{a}$ and c), thanks to the instability of vertical plates, which have a relative large slenderness ratio, while the sample 3 is nearly symmetric (Fig. 4e). When the samples fail, the plastic hinges and fracture points locate at the plate-shell connecting points on the plates (points A and B, Fig. 4g) or on the cylindrical shell (points C, Fig. 4h), depending on the $r / l$ ratio. This behaviour has already been verified by the theoretical analysis [19]. For the $y$ direction, the three samples share a symmetric configuration (Fig. 5a,c, and e), but their failures differ as well, since in the samples 1 and 2 (i.e., $r / l=0.2,0.3$ ) plastic hinges and fractures occur in the two plates (points A in Fig. 5g), while on the cylindrical shell in the the sample 3 ( $r / l=0.4$, points $\mathrm{C}$ in Fig. $5 \mathrm{~h}$ ). The same occurs in the samples loaded in the $x$ direction. The contours of von Mises stresses from the finite element simulations confirm the results, see Figs. $4 \mathrm{i}$ and $5 \mathrm{i}$. 
This is the post-print version of the article Q. Chen, Q. Shi, S. Signetti, F. Sun, Z. Li, F. Zhu, S. He, N.M. Pugno. Plastic collapse of cylindrical shell-plate periodic honeycombs under uniaxial compression: experimental and numerical analyses. Int. J. Mech. Sci. 111-112:125-133, 2016 available in its final version at the following URL: http://dx.doi.org/10.1016/j.ijmecsci.2016.03.020

\subsection{Out-of-plane mechanical behaviour}

Like the in-plane case, the FEM and experimental stress-strain curves and the yield strength to mass ratio of the five out-of-plane samples are plotted in Fig. 6. In Fig. 6a, the portions (marked by I, II and III) between elastic limit and yield stress of the strain-stress curves of the sample 2, 3, 4 is longer than those of the samples 1 and 5. This is because in the loading process, the three samples underwent different but slight shear effect, which reduced the samples' yield strength. Moreover, when $r / l$ is small (samples 1-3), there is only one couple of peak and valley; while $r / l$ is large (samples 4, 5), there are multi-couples of peak and valley (1) (4)), and the plateau stage is much longer than those of the samples with small $r / l$, but sample $3(r / l=0.3)$ still possesses the greatest energy-absorption capacity (computed as the area under the stressstrain curve). And more, it is readily seen that there are jumps (dashed squares in Fig. 6a) in the strain-stress curves for samples 2 and 4, and this is due to the cell-wall brittle fracture. Besides, the FEM compression tests are shown in Fig. 6a1-a3.

Young's moduli reflected by the slopes of the linear-elastic stages are approximately same (Fig. 6a), and this can be explained through the classical predication by $E^{*} / E_{\mathrm{c}}=\rho^{*} / \rho^{\mathrm{c}}[10]$, and here $\rho^{*} / \rho^{c}$ is a constant. Young's moduli from FEM result are much larger than those from experiments, and the reason can be referred to the in-plane cases.

The yield strengths of the five samples are $35.95 \mathrm{MPa}(r / l=0.0), 35.46 \mathrm{MPa}(r / l=0.2)$, $38.78 \mathrm{MPa}(r / l=0.3), 30.60 \mathrm{MPa}(r / l=0.4), 27.81 \mathrm{MPa}(r / l=0.5)$ for experiments $v s .34 .99 \mathrm{MPa}$, 34.51 MPa, 38.06 MPa, 29.09 MPa, 26.80 MPa for finite element simulations. The yield strength of the out-of-plane samples is 20-30 times those of the in-plane samples. The optimized yield strength is obtained as well when $r / l=0.3$, and the same for the yield strength to mass ratio (Fig. 6b) due to the weak mass variation of the intra-group (out-of-plane) samples. However, different from the in-plane samples, the FEM results are lower than their experimental counterparts.

As an interesting example, we snapshotted four peak-valley states of the sample 5 assembled only by cylindrical shells without plates, and the sequence of events is shown in Fig. 7. Initially, the entire sample deforms elastically to the first peak point, i.e., yield stress. Due to the existence of the bottom steel plate, the further expansion of the sample's deformation is restrained, and the first axisymmetric outward fold $(n=1)$ starts to form; as the load increases, the fold of each cylindrical shell grows and it thrusts into its adjacent shells to form an overlap (the arrows in (1) of Fig. 7), while the rest of the sample still deforms elastically. 
This is the post-print version of the article Q. Chen, Q. Shi, S. Signetti, F. Sun, Z. Li, F. Zhu, S. He, N.M. Pugno. Plastic collapse of cylindrical shell-plate periodic honeycombs under uniaxial compression: experimental and numerical analyses. Int. J. Mech. Sci. 111-112:125-133, 2016 available in its final version at the following URL: http://dx.doi.org/10.1016/j.ijmecsci.2016.03.020

Simultaneously, the constituent material at the fold begins to yield, and the entire sample shows a softening behaviour. Then, the deformation of the portion close to the fold accumulates. After the contact of the two sides in the fold, the drop of the compressive load arrests. Meanwhile, a new diamond fold $(n=2)$ starts to form, and the second peak stress gradually emerges, followed by the second valley. In state (2), the overlaps (the arrows in (2) of Fig. 7) can be clearly seen. After the state (2), the third and fourth diamond folds (states (3) and (4) are formed by the squeezed cylindrical shells (the arrows in (3) and (4) of Fig. 7), and the stress does not apparently increase until it reaches the densification of state (4), after which, the stress increases sharply.

\section{Discussions}

To date, a number of lattice structures have been studied and defined [7]. Here, the structure is discussed in a new sense, i.e., it is regarded as a periodic combination of plate and cylindrical shells, which are two basic elements in structural mechanics. As $r / l$ rises, the contribution of the plate decreases but the one of cylindrical shell increases, and these complementary tendencies optimize the mechanical behaviour of the structure. Not losing generality, we consider this as an optimized spatial arrangement of $n$ substructures. The general mechanical behaviour $F$ of the structure is expressed as the sum of the $n$ substructures:

$$
F=\sum_{i=1}^{n} f_{i}\left(M_{i}, S_{i}, P_{i}\right)
$$

where $f_{\mathrm{i}}$ represents the mechanical contribution of the $i$-th substructure, $M_{\mathrm{i}}, S_{\mathrm{i}}$ and $P_{\mathrm{i}}$ are mechanics-parametric, size and positional information of the $i$-th substructure, respectively. The general mechanical behaviour $F$ in Eq. (1) can be the force-displacement curve, elastic modulus, strength, toughness, and other mechanical properties. As we know, for a structure, the selection of bulk materials (i.e., $M_{\mathrm{i}}$ ) could be referred to Ashby's maps [10], which provide materials indices for mechanical designs according to stiffness, strength and other variables. Then, mechanical properties of the structure can be obtained by varying the size $\left(S_{\mathrm{i}}\right)$ and spatial arrangement $\left(P_{\mathrm{i}}\right)$ of the substructures. Therefore, given a constituent material, for the optimization, we have:

$$
\frac{\partial F}{\partial S_{i}}=0 \text { and } \frac{\partial F}{\partial P_{i}}=0
$$


This is the post-print version of the article Q. Chen, Q. Shi, S. Signetti, F. Sun, Z. Li, F. Zhu, S. He, N.M. Pugno. Plastic collapse of cylindrical shell-plate periodic honeycombs under uniaxial compression: experimental and numerical analyses. Int. J. Mech. Sci. 111-112:125-133, 2016 available in its final version at the following URL: http://dx.doi.org/10.1016/j.ijmecsci.2016.03.020

The present structure, with the specific relative density (i.e., $\rho^{*} / \rho^{c}=0.1$ ), is a peculiar case of the above optimized solution with the 6061-T4 Aluminum-alloy material $\left(M_{\mathrm{i}}\right)$, fixed positions of the plate and cylindrical shell $\left(P_{\mathrm{i}}\right)$, and two substructures $(n=2)$. Thus, the only factor to be optimized is the size variable $r / l$, and the optimized value is about 1/3. Considering Eq. (1), we find the simple expression:

$$
\frac{F}{f_{i}}=1+\frac{f_{j}}{f_{i}} \quad(i \neq j ; i, j=P \text { or } C S)
$$

where $f_{\mathrm{i}}$ and $f_{\mathrm{j}}$ are functions of the honeycomb's relative density $\rho^{*} / \rho^{\mathrm{c}}=0.1$ and of the size variable $r / l$, and they denote the mechanical behaviours of plates $(P)$ or cylindrical shells $(C S)$, respectively. For a specific case, in the linear-elastic stage, we consider $F, f_{\mathrm{P}}$ and $f_{\mathrm{CS}}$ as the bending elastic strain energies of the whole structure, plates and cylindrical shells, respectively. According to the calculation of the strain energy by the authors' previous work [19], the competitive relation of the two parts is plotted in Fig. 8, from which we can clearly see that the contributions of plates and shells in the linear-elastic deformation of the honeycomb when $r / l$ varies.

\subsection{In-plane loaded samples}

We have shown the mechanical behaviour of the six samples in Section 3.1. The feature is that the samples 2 (both $x$ and $y$ directions) have two different linear-elastic and plateau stages in experiments. According to Eq. (3), for the two extreme cases, if $r / l \rightarrow 0$, the cylindrical shells disappear, i.e., $f_{\mathrm{CS}}=0$, and the structure shrinks into the conventional regular hexagonal honeycomb, which has been widely studied in literature. Thus, we have $F=f_{\mathrm{P}}$; otherwise, when $r / l \rightarrow 0.5$, the plates disappear, i.e. , $F=f_{\mathrm{CS}}$. For the structures in-between, smaller $r / l$ ratio $(e . g$., sample 1) results in a more rigid cylindrical shells, and the in-plane samples fail in the weaker plates due to bending and buckling; on the contrary, greater $r / l$ (e.g., sample 3 ) results in a more compliant cylindrical shell, and the samples fail in the weaker cylindrical shell due to their bending. These two cases result in single pair of linear elastic and plastic stages as shown in Fig. 3a and b. When $f_{\mathrm{P}}$ is comparable to $f_{\mathrm{CS}}$, the two parts fail one after the other, namely, if $f_{\mathrm{P}}<f_{\mathrm{CS}}$, the plate fails before the cylindrical shell, which is the case of sample 2 . This causes the double pairs of linear elastic and plastic stages, E1-P1 and E2-P2 in Fig. 3a and b: the first one is contributed by the bending and yielding of the plate, and the second by the bending and collapse of the cylindrical shell. In view of this, it can be concluded that it is the featured 
This is the post-print version of the article Q. Chen, Q. Shi, S. Signetti, F. Sun, Z. Li, F. Zhu, S. He, N.M. Pugno. Plastic collapse of cylindrical shell-plate periodic honeycombs under uniaxial compression: experimental and numerical analyses. Int. J. Mech. Sci. 111-112:125-133, 2016 available in its final version at the following URL: http://dx.doi.org/10.1016/j.ijmecsci.2016.03.020

structure that provides the sample 2 with the optimized failure mechanism and further best energy-absorption ability even though the six samples have approximate mass. In this regard, the one-after-another failure mechanism of different components in the structure is similar to the hierarchical behaviour of spider silk [26], which enables its great extensibility, toughness and strength.

\subsection{Out-of-plane loaded samples}

In the loading process, the samples 1 and 5 were compressed almost aligned with the centroid of the imprint area of the two samples. The collapsed samples and their failure mechanisms are shown in Fig. 9. For the sample 1, the collapse of the structure, caused by the plate, is a classical problem, and the plastic strength is simply predicted by:

$$
\frac{\sigma^{*}}{\sigma_{y s}^{c}}=C(\lambda, \varphi)\left(\frac{\rho^{*}}{\rho^{c}}\right)^{2}
$$

where, $\sigma^{*}$ and $\sigma_{\text {ys }}^{\mathrm{c}}$ are yield strengths of the structure and its constituent material, and $C$ is a constant, which depends on the lobe's wavelength $\lambda$ and the rotational angle $\phi$ of the plastic hinge. The black circled part (upper one in Fig. 9a) is representative because its boundary condition is close to that of the unit cell in multi-cell structures (only three unit cells here). The failed plates exhibit an anticlockwise trichiral arrangement, and only one lobe and fracture mouth forms (highlighted by the arrow in Fig. 9a), which depends on the structural geometry and mechanical behaviour of its constituent materials.

For the sample 5, the collapse of the structure is caused by the cylindrical shell. For single cylindrical tube, many works explain its collapse mechanisms [27-29]. In particular, depending on thickness, diameter and length, Andrews et al. [29] classified collapse modes of cylindrical tubes into seven groups from concertina to tilting of the tube axis, basing on tested 189 annealed Ht-30 Aluminium alloy tubes. However, the cylindrical shell in the present structure is different from the single cylindrical tube, because of the restrains of its adjacent cylindrical shells (red circled points in Fig. 9b). In this case, the three-lobe collapse is prone to occur. Besides, we find that the sample 1 has a larger fold size and less fold number than those of the sample 5 .

For the samples $2-4$, their collapse is contributed by both parts, i.e., plate and cylindrical shell (Fig. 10). Combining the extreme case $(r / l=0$ and $r / l=0.5)$ discussed above, we can conclude that as $r / l$ increases (Fig. 10), the substructure dominating the collapse of honeycombs again changes from the plates to cylindrical shells, as predicted by Eq. (3). The numbers of 
This is the post-print version of the article Q. Chen, Q. Shi, S. Signetti, F. Sun, Z. Li, F. Zhu, S. He, N.M. Pugno. Plastic collapse of cylindrical shell-plate periodic honeycombs under uniaxial compression: experimental and numerical analyses. Int. J. Mech. Sci. 111-112:125-133, 2016 available in its final version at the following URL: http://dx.doi.org/10.1016/j.ijmecsci.2016.03.020

folds in plates and cylindrical shells are mutually dependent, see the arrows in Fig. 10d, and the fold number increases for increasing $r / l$, and correspondingly, their wavelength decreases. Finally, due to the instability of the plates and cylindrical shells, marked by ellipses in Fig. 10ac, the shear effect as stated before is introduced, and this corresponds to the three stages (I, II, III) in Fig. 6a.

\section{Conclusions}

In this paper, we studied the mechanical behaviour of a set of cylindrical shell-plate assembled honeycombs. Through experiments and FEM numerical simulations carried on in-plane and out-of-plane loaded samples, their plastic collapse mechanisms were observed and analyzed. Young's modulus and yield strength of the honeycombs were optimized when $r / l=0.3$. In particular, when $r / l=0.3$, the in-plane loaded samples exhibited a functional gradient property since the plates failed after the cylindrical shells, while the out-of-plane direction was associated to the best energy-absorption capacity. Meanwhile, the developed numerical model was verified to be able to describe the experiments and could be used in the studies of future-developed honeycombs. Most of all, it indicates that the combination of hollow cylindrical shells and plates forms a new periodic assembly with better mechanical properties with respect to conventional honeycombs. This strategy may be used to generate new lattices for enhanced crashworthy structures.

\section{Acknowledgements}

This work was partially supported by the National Natural Science Foundation of China (NSFC) (Nos. 31300780, 11272091, and 11572087, 11572087) and the Fundamental Research Funds for the Central Universities (No. 2242016R30014). NMP is supported by the European Research Council (ERC StG Ideas 2011 BIHSNAM n. 279985, ERC PoC 2013 KNOTOUGH n. 632277, ERC PoC 2015 SILKENE n. 693670) and by the European Commission under the Graphene Flagship (WP "Nanocomposites", n. 696656). SS acknowledges support from BIHSNAM. 
This is the post-print version of the article Q. Chen, Q. Shi, S. Signetti, F. Sun, Z. Li, F. Zhu, S. He, N.M. Pugno. Plastic collapse of cylindrical shell-plate periodic honeycombs under uniaxial compression: experimental and numerical analyses. Int. J. Mech. Sci. 111-112:125-133, 2016 available in its final version at the following URL: http://dx.doi.org/10.1016/j.ijmecsci.2016.03.020

\section{References}

[1] Chen Q, Shi Q, Gorb S, Li Z. A multiscale study on the structural and mechanical properties of the luffa sponge from Luffa cylindrica plant. J Biomech 2014;47:1332-9.

[2] Zheng J, Zhao L, Fan H. Energy absorption mechanisms of hierarchical woven lattice composites. Compos Part B-Eng 2012;43:1516-22.

[3] Boldrin L, Scarpa F, Rajasekaran R. Thermal conductivities of iso-volume centresymmetric honeycombs. Compos Struct 2014;113:498-506.

[4] Sun Y, Chen Q, Pugno N. Elastic and transport properties of the tailorable multifunctional hierarchical honeycombs. Compos Struct 2014;107:698-710.

[5] Huynen I, Quiévy N, Bailly C, Bollen P, Detrembleur C, Eggermont S, Molenberg I, Thomassin JM, Urbanczyk L, Pardoen T. Multifunctional hybrids for electromagnetic absorption. Acta Mater 2011;59:3255-66.

[6] Wang AJ, McDowell DL. In-plane stiffness and yield strength of periodic metal honeycombs. J Eng Mater Technol 2004;126:137-56.

[7] Wadley HNG. Multifunctional periodic cellular metals. Phil Trans R Soc A 2006;364:3168.

[8] Papka SD, Kyriakides S. In-plane compressive response and crushing of honeycomb. $J$ Mech Phys Solids 1994;42:1499-532.

[9] Papka SD, Kyriakides S. In-plane crushing of a polycarbonate honeycomb. Int J Solids Struct 1998;35:239-67.

[10] Gibson LJ, Ashby MF. Cellular solids: structure and properties. 2nd ed. Cambridge: Cambridge University Press; 1997.

[11] Chen Q, Pugno N. In-plane elastic buckling of hierarchical honeycomb materials. Eur J Mech A/Solids 2012;34:120-9.

[12] Fan H, Jin F, Fang D. Mechanical properties of hierarchical cellular materials. Part I: Analysis. Compos Sci Tech 2008;68:3380-7.

[13] Taylor CM, Smith CW, Miller W, Evans KE. The effects of hierarchy on the in-plane elastic properties of honeycombs. Int J Solids Struct 2011;48:1330-9.

[14] Sun Y, Pugno N. In plane stiffness of multifunctional hierarchical honeycombs with negative Poisson's ratio sub-structures. Compos Struct 2013;106:681-9.

[15] Banerjee S. On the mechanical properties of hierarchical lattices. Mech Mater 2014;72:19-32.

[16] Oftadeh R, Haghpanah B, Papadopoulos J, Hamouda AMS, Nayeb-Hashemi H, Vaziri A. Mechanics of anisotropic hierarchical honeycombs. Int J Mech Sci 2014;81:126-36. 
This is the post-print version of the article Q. Chen, Q. Shi, S. Signetti, F. Sun, Z. Li, F. Zhu, S. He, N.M. Pugno. Plastic collapse of cylindrical shell-plate periodic honeycombs under uniaxial compression: experimental and numerical analyses. Int. J. Mech. Sci. 111-112:125-133, 2016 available in its final version at the following URL: http://dx.doi.org/10.1016/j.ijmecsci.2016.03.020

[17] Haghpanah B, Papadopoulos J, Vaziri A. Plastic collapse of lattice structures under a general stress state. Mech Mater 2014;68:267-74.

[18] Yi T. Mechanical properties of a hierarchical honeycomb with sandwich walls. 2016;230: 2765-2775.

[19] Chen Q, Pugno N, Zhao K, Li Z. Mechanical properties of a hollow-cylindrical-joint honeycomb. Compos Struct 2014;109:68-74

[20] Xia R, Feng XQ, Wang GF. Effective elastic properties of nanoporous materials with hierarchical structure. Acta Mater 2011;59:6801-8.

[21] Chen Q, Pugno N. In-plane elastic properties of hierarchical nano-honeycombs: The role of the surface effect. Eur J Mech A/Solids 2013;37:248-55.

[22] Miller W, Smith CW, Scarpa F, Evans KE. Flatwise buckling optimization of hexachiral and tetrachiral honeycombs. Compos Sci Tech 2010;70:1049-56.

[23] Shen Z, Yang X, Yang S, Zhang Z, Yin Y. Microstructure and mechanical properties of friction spot welded 6061-T4 aluminum alloy. Mater Design 2014;54:766-78.

[24] Sun F, Lai C, Fan H, Fang DN. Crushing mechanism of hierarchical lattice structure. Mech Mater 2016;97:164-87.

[25] Hong W, Fan H, Xia Z, Jin F, Zhou Q, Fang D. Axial crushing behaviors of multi- cell tubes with triangular lattices. Int J Impact Eng 2014;63:106-17.

[26] Giesa T, Arslan M, Pugno NM, Buehler MJ. Nanoconfinement of spider silk fibrils begets superior strength, extensibility, and toughness. Nano Lett 2011;11:5038-46.

[27] Alexander JM. An approximate analysis of the collapse of thin cylindrical shells under axial load. Q J Mech Appl Math 1960;13:10-5.

[28] Johnson W, Soden PD, Al-Hassani STS. Inextensional collapse of thin-walled tubes under axial compression. J Strain Anal Eng 1977;12:317-30.

[29] Andrews KRF, England GL, Ghani E. Classification of the axial collapse of cylindrical tubes under quasi-static loading. Int J Mech Sci 1983;25:687-96. 
This is the post-print version of the article Q. Chen, Q. Shi, S. Signetti, F. Sun, Z. Li, F. Zhu, S. He, N.M. Pugno. Plastic collapse of cylindrical shell-plate periodic honeycombs under uniaxial compression: experimental and numerical analyses. Int. J. Mech. Sci. 111-112:125-133, 2016 available in its final version at the following URL: http://dx.doi.org/10.1016/j.ijmecsci.2016.03.020

\section{Figures and tables}

Table 1. Geometric parameters and masses $(m)$ of the eleven samples, note that the numbers in the parentheses denote the masses of the samples compressed in the $y$ direction.

\begin{tabular}{|c|c|c|c|c|c|c|c|c|c|c|c|c|}
\hline \multirow{2}{*}{$\begin{array}{c}\text { Geometry of a unit } \\
\text { cell }\end{array}$} & \multirow[b]{2}{*}{ n. } & \multicolumn{5}{|c|}{ In-plane } & \multirow[b]{2}{*}{ n. } & \multicolumn{5}{|c|}{ Out-of-plane } \\
\hline & & $\begin{array}{c}l \\
{[\mathrm{~mm}]}\end{array}$ & $\begin{array}{c}r \\
{[\mathrm{~mm}]}\end{array}$ & $\begin{array}{c}t \\
{[\mathrm{~mm}]}\end{array}$ & $\begin{array}{l}m \\
{[g]}\end{array}$ & $\begin{array}{l}m_{\mathrm{re}} \\
{[\mathrm{g}]}\end{array}$ & & $\begin{array}{c}l \\
{[\mathrm{~mm}]}\end{array}$ & $\begin{array}{c}r \\
{[\mathrm{~mm}]}\end{array}$ & $\begin{array}{c}t \\
{[\mathrm{~mm}]}\end{array}$ & $\begin{array}{l}m \\
{[\mathrm{~g}]}\end{array}$ & $\begin{array}{l}m_{\mathrm{re}} \\
{[\mathrm{g}]}\end{array}$ \\
\hline & - & - & - & - & & - & 1 & 20 & 0 & 1.78 & 41.7 & 39.6 \\
\hline & 1 & 20 & 4 & 1.26 & 59.9 & $\begin{array}{c}55.8 \\
(53.1)\end{array}$ & 2 & 20 & 4 & 1.26 & 41.7 & 38.9 \\
\hline & 2 & 20 & 6 & 1.08 & 59.9 & $\begin{array}{c}55.0 \\
(52.3)\end{array}$ & 3 & 20 & 6 & 1.08 & 41.7 & 39.8 \\
\hline & 3 & 20 & 8 & 0.95 & 59.9 & $\begin{array}{c}56.7 \\
(53.2)\end{array}$ & 4 & 20 & 8 & 0.95 & 41.7 & 36.5 \\
\hline & - & - & - & - & & - & 5 & 20 & 10 & 0.84 & 41.7 & 34.6 \\
\hline
\end{tabular}

a

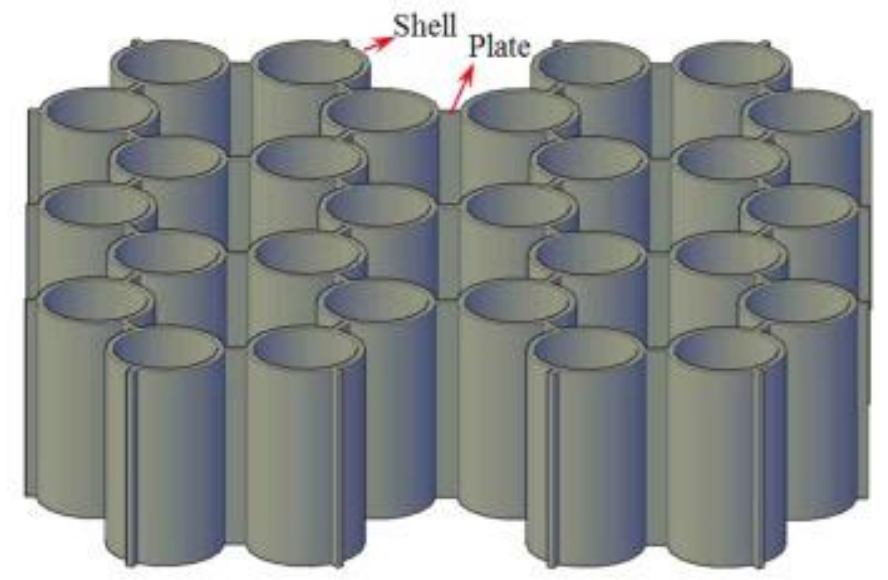

b

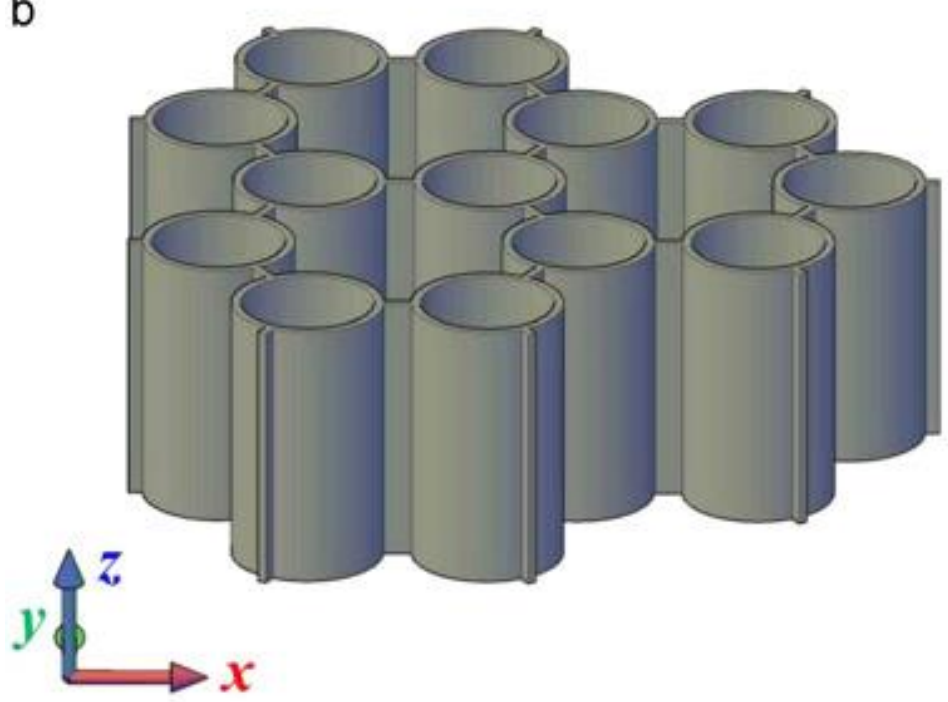

Figure 1. Images of (a) an in-plane loaded sample and (b) an out-of-plane loaded sample. 
This is the post-print version of the article Q. Chen, Q. Shi, S. Signetti, F. Sun, Z. Li, F. Zhu, S. He, N.M. Pugno. Plastic collapse of cylindrical shell-plate periodic honeycombs under uniaxial compression: experimental and numerical analyses. Int. J. Mech. Sci. 111-112:125-133, 2016 available in its final version at the following URL: http://dx.doi.org/10.1016/j.ijmecsci.2016.03.020

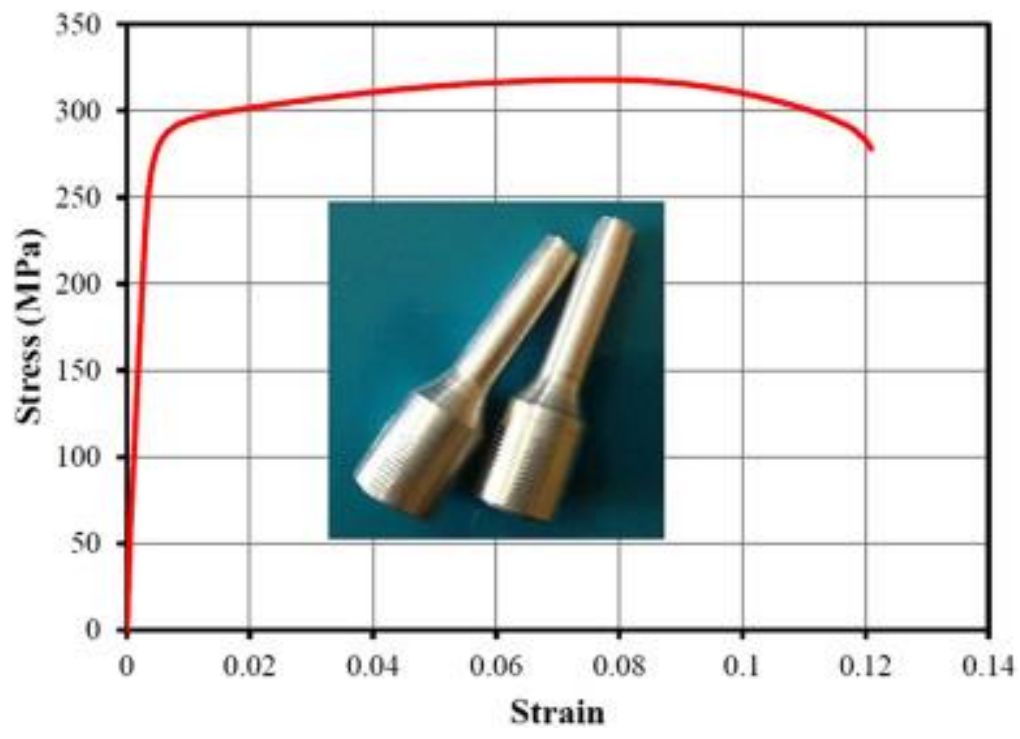

Figure 2. Stress-strain curve of 6061-T4 aluminum alloy used for the fabrication of honeycombs, obtained from tensile test on a dog bone specimen (picture of the failed specimen depicted within the graph).

a

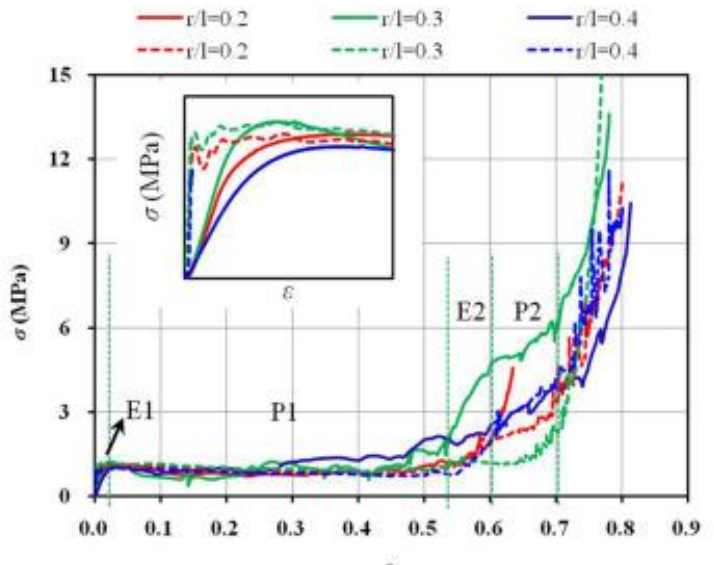

。

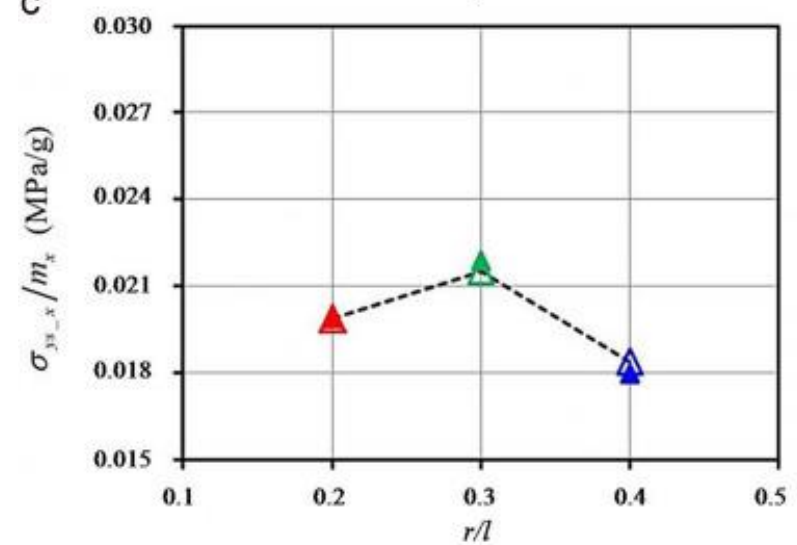

b

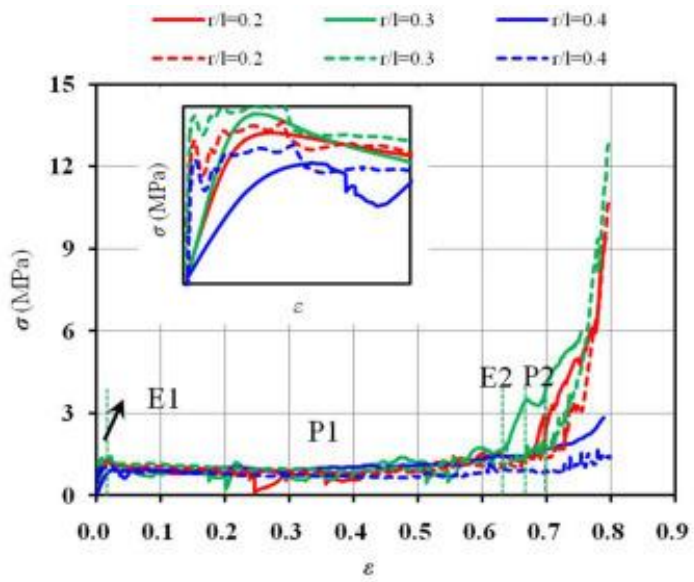

d

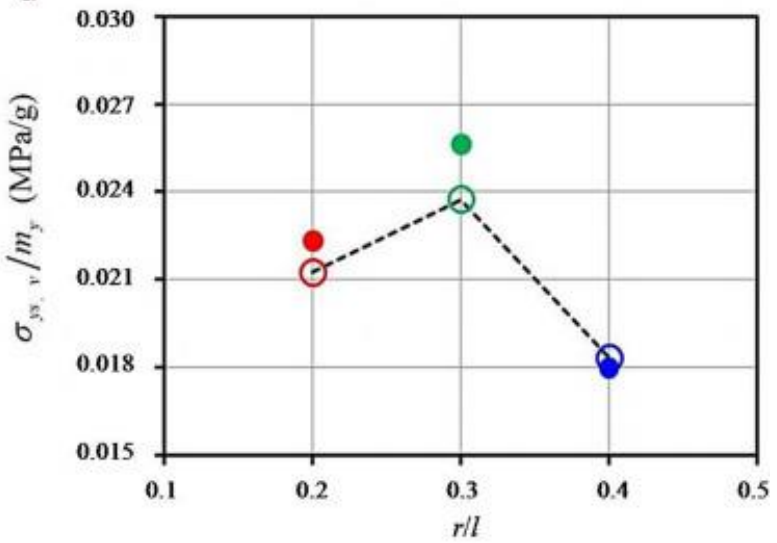

Figure 3. Stress-strain curves of the sample loaded in (a) $x$ direction and (b) $y$ directions showing experimental (solid lines) and FEM (dashed lines) results. Yield strength to mass ratio for (c) $x$ direction and (d) $y$ direction with comparison between experiments (filled markers) and FEM (unfilled markers connected by dashed lines). 
This is the post-print version of the article Q. Chen, Q. Shi, S. Signetti, F. Sun, Z. Li, F. Zhu, S. He, N.M. Pugno. Plastic collapse of cylindrical shell-plate periodic honeycombs under uniaxial compression: experimental and numerical analyses. Int. J. Mech. Sci. 111-112:125-133, 2016 available in its final version at the following URL: http://dx.doi.org/10.1016/j.ijmecsci.2016.03.020
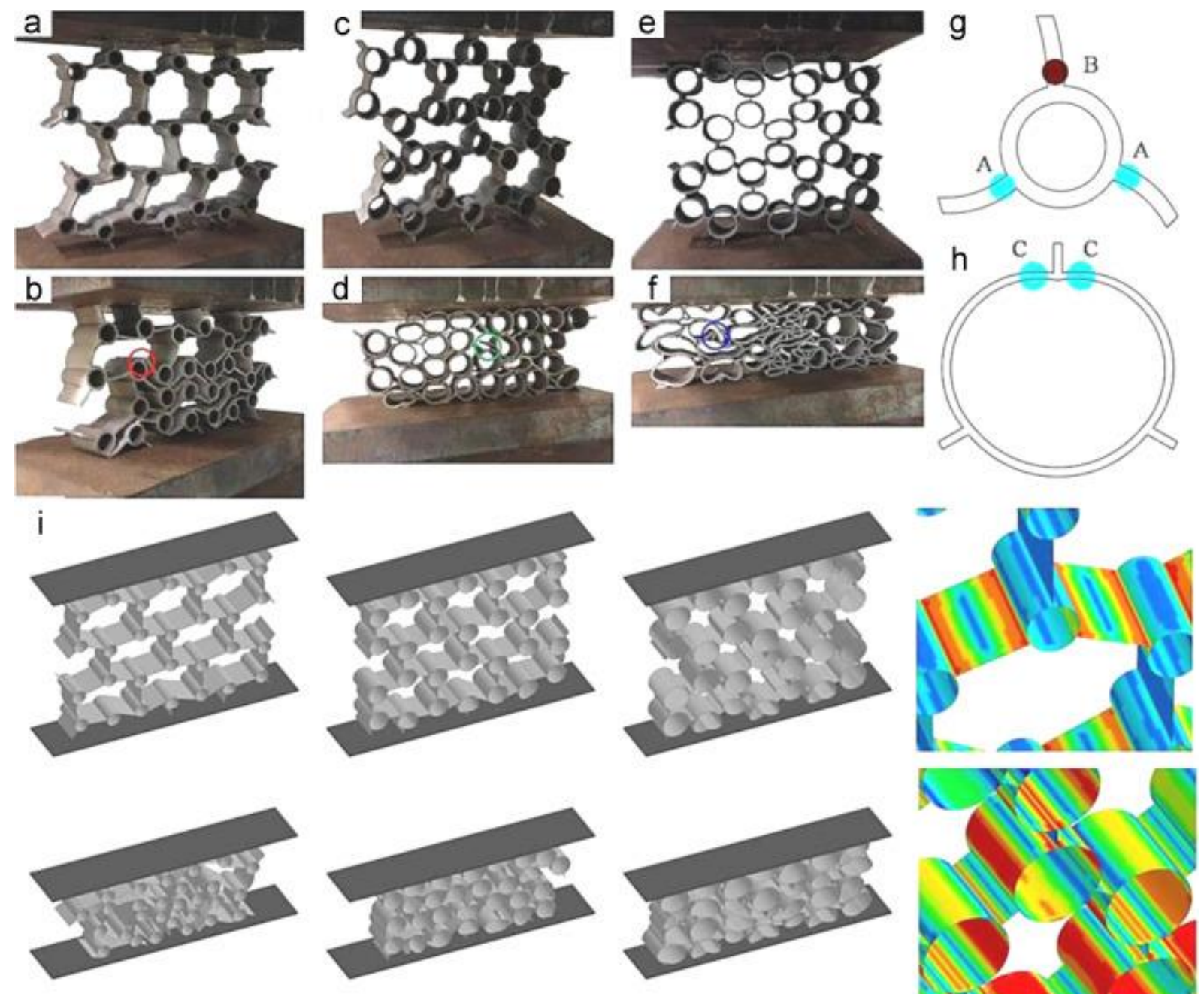

Figure 4. Snapshots of the experimental in-plane loaded samples in the $x$ direction with $r / l=0.2$ (a and b) $r / l=0.3$ (c and d) $r / l=0.4$ (e and f) at two different strain levels. (i) Corresponding snapshots from finite element simulations and details of the cylindrical shell-plate joints for different $r / l$ with contour of von Mises stress (red regions are the most stressed). The solid coloured circles in ( $g$ and $h$ ) represent the plastic hinges or fracture locations corresponding to the empty circles in (b, $d$ and $f$ ). 
This is the post-print version of the article Q. Chen, Q. Shi, S. Signetti, F. Sun, Z. Li, F. Zhu, S. He, N.M. Pugno. Plastic collapse of cylindrical shell-plate periodic honeycombs under uniaxial compression: experimental and numerical analyses. Int. J. Mech. Sci. 111-112:125-133, 2016 available in its final version at the following URL: http://dx.doi.org/10.1016/j.ijmecsci.2016.03.020
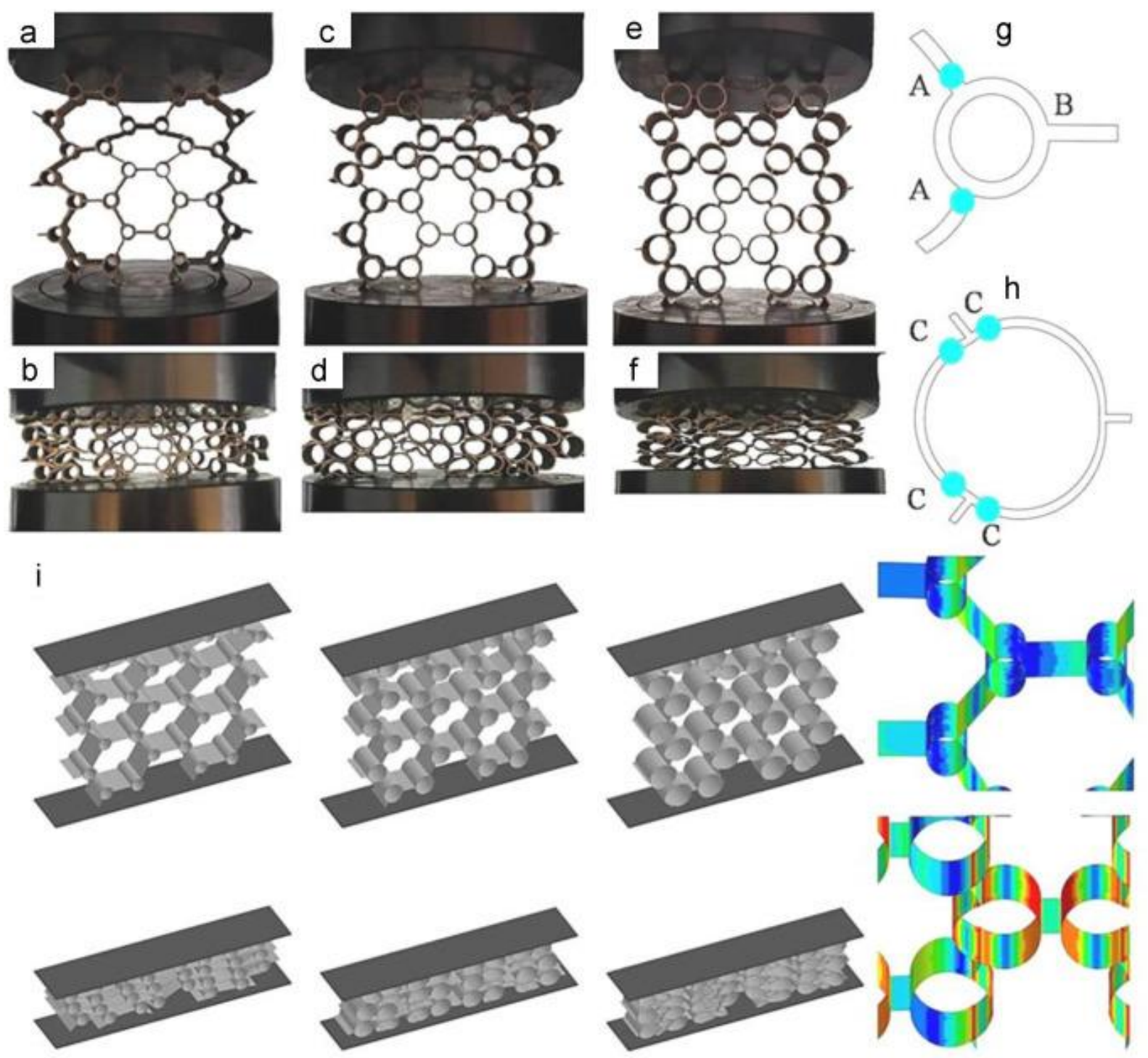

Figure 5. Snapshots of the experimental in-plane loaded samples in the $y$ direction with $r / l=0.2$ (a and b) $r / l=0.3$ (c and d) $r / l=0.4$ (e and f) at two different strain levels. (i) Corresponding snapshots from finite element simulations and details of the cylindrical shell-plate joints for different $r / l$ with contour of von Mises stress. The solid coloured circles in ( $g$ and $h$ ) represent the plastic hinge or fracture locations. 
This is the post-print version of the article Q. Chen, Q. Shi, S. Signetti, F. Sun, Z. Li, F. Zhu, S. He, N.M. Pugno. Plastic collapse of cylindrical shell-plate periodic honeycombs under uniaxial compression: experimental and numerical analyses. Int. J. Mech. Sci. 111-112:125-133, 2016 available in its final version at the following URL: http://dx.doi.org/10.1016/j.ijmecsci.2016.03.020

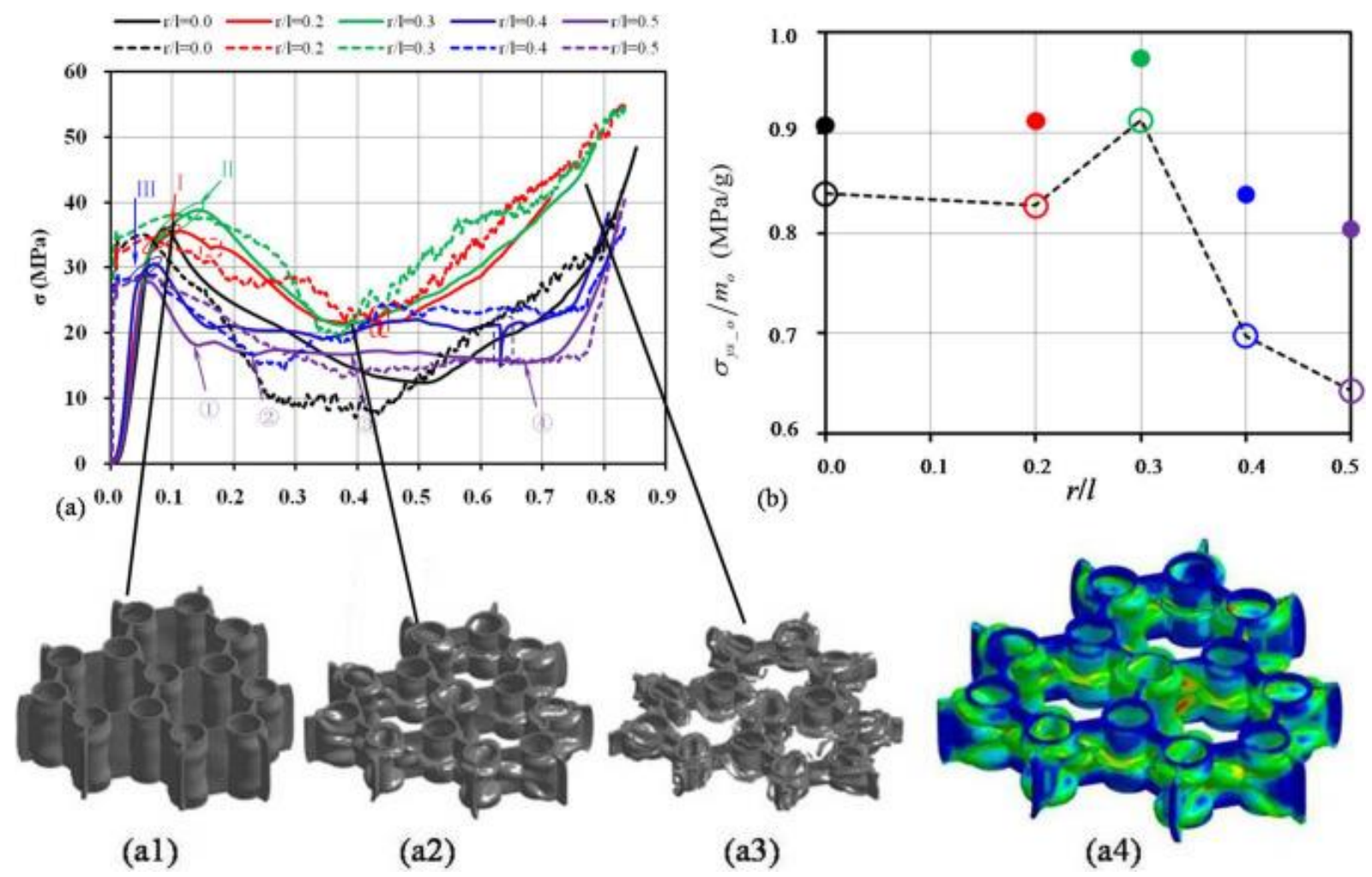

Figure 6. Comparison between experimental (solid lines) and finite element simulations (dashed lines) results of out-of-plane loaded samples. (a) Strain-stress curves of the five samples, and snapshots from the finite element simulations of the optimized structure at three states and the contour of plastic strain of the second state and (b) yield strength to mass ratios of the five samples: filled and dashed-line connected unfilled spots represents the experimental and FEM results, respectively. Note: the sample $1(r / l=0.0)$ denotes the conventional regular hexagonal honeycomb. 
This is the post-print version of the article Q. Chen, Q. Shi, S. Signetti, F. Sun, Z. Li, F. Zhu, S. He, N.M. Pugno. Plastic collapse of cylindrical shell-plate periodic honeycombs under uniaxial compression: experimental and numerical analyses. Int. J. Mech. Sci. 111-112:125-133, 2016 available in its final version at the following URL: http://dx.doi.org/10.1016/j.ijmecsci.2016.03.020

a
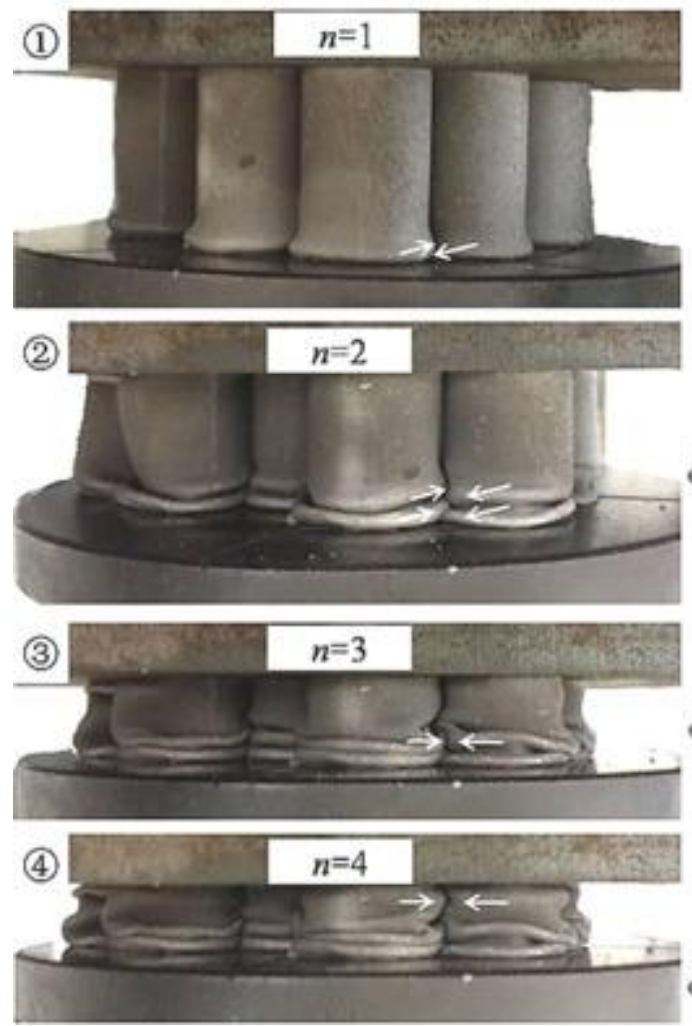

b
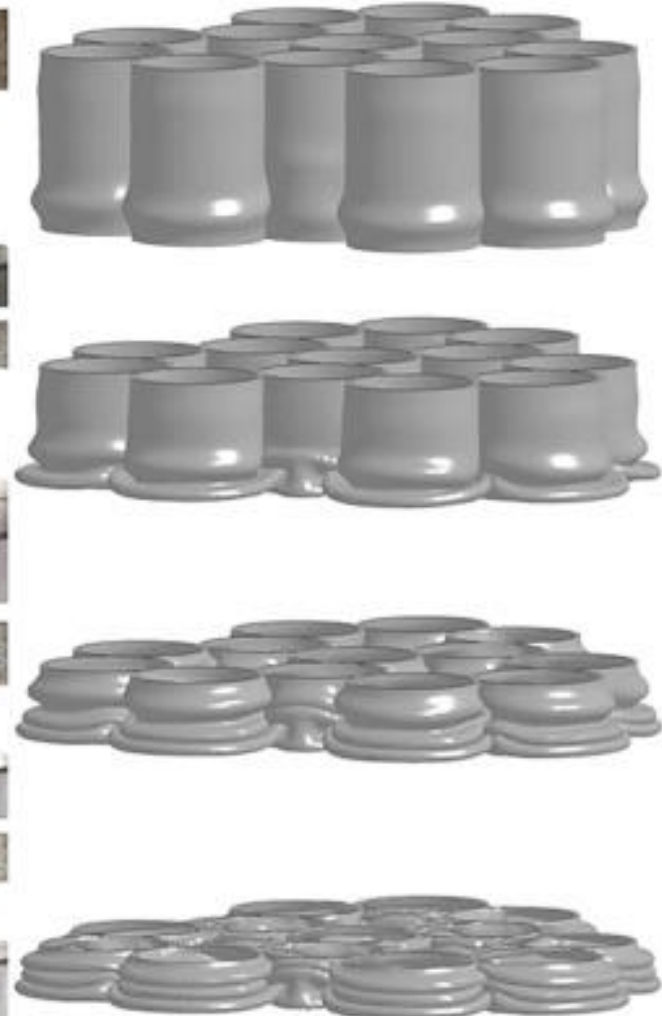

Figure 7. Snapshots of four folds in the loaded sample 5: (a) experiment and (b) finite element simulation.

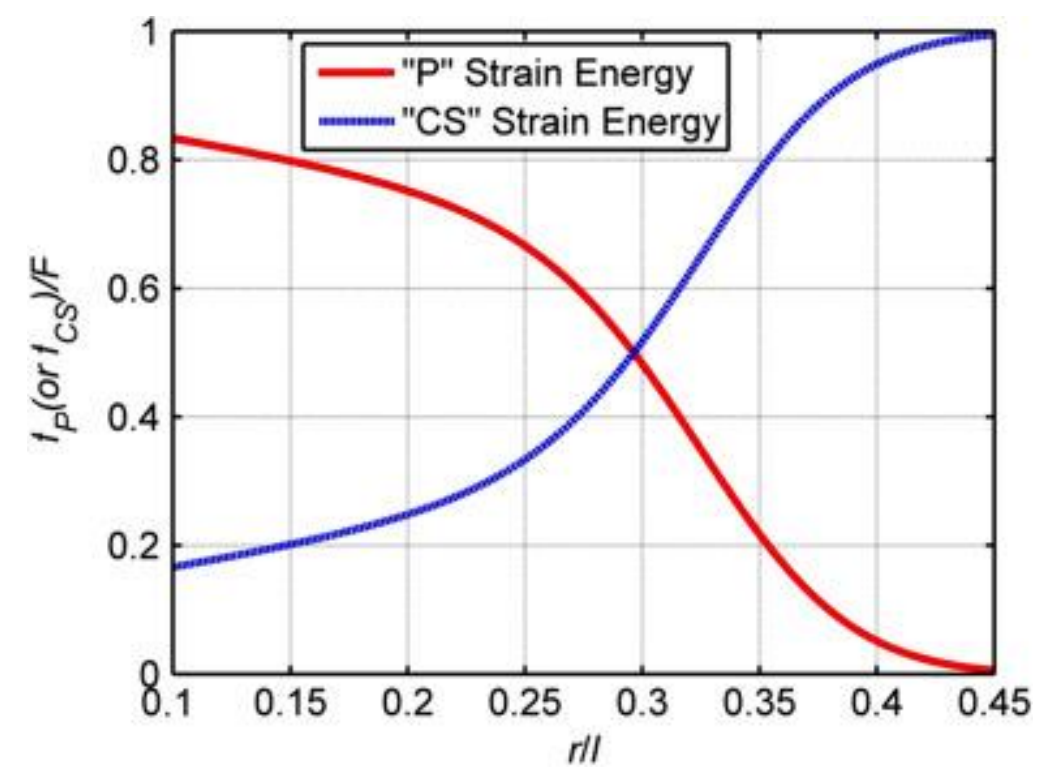

Figure 8. Competition of elastic strain energies between the plate and the cylindrical shell as $r / l$ varies. 
This is the post-print version of the article Q. Chen, Q. Shi, S. Signetti, F. Sun, Z. Li, F. Zhu, S. He, N.M. Pugno. Plastic collapse of cylindrical shell-plate periodic honeycombs under uniaxial compression: experimental and numerical analyses. Int. J. Mech. Sci. 111-112:125-133, 2016 available in its final version at the following URL: http://dx.doi.org/10.1016/j.ijmecsci.2016.03.020
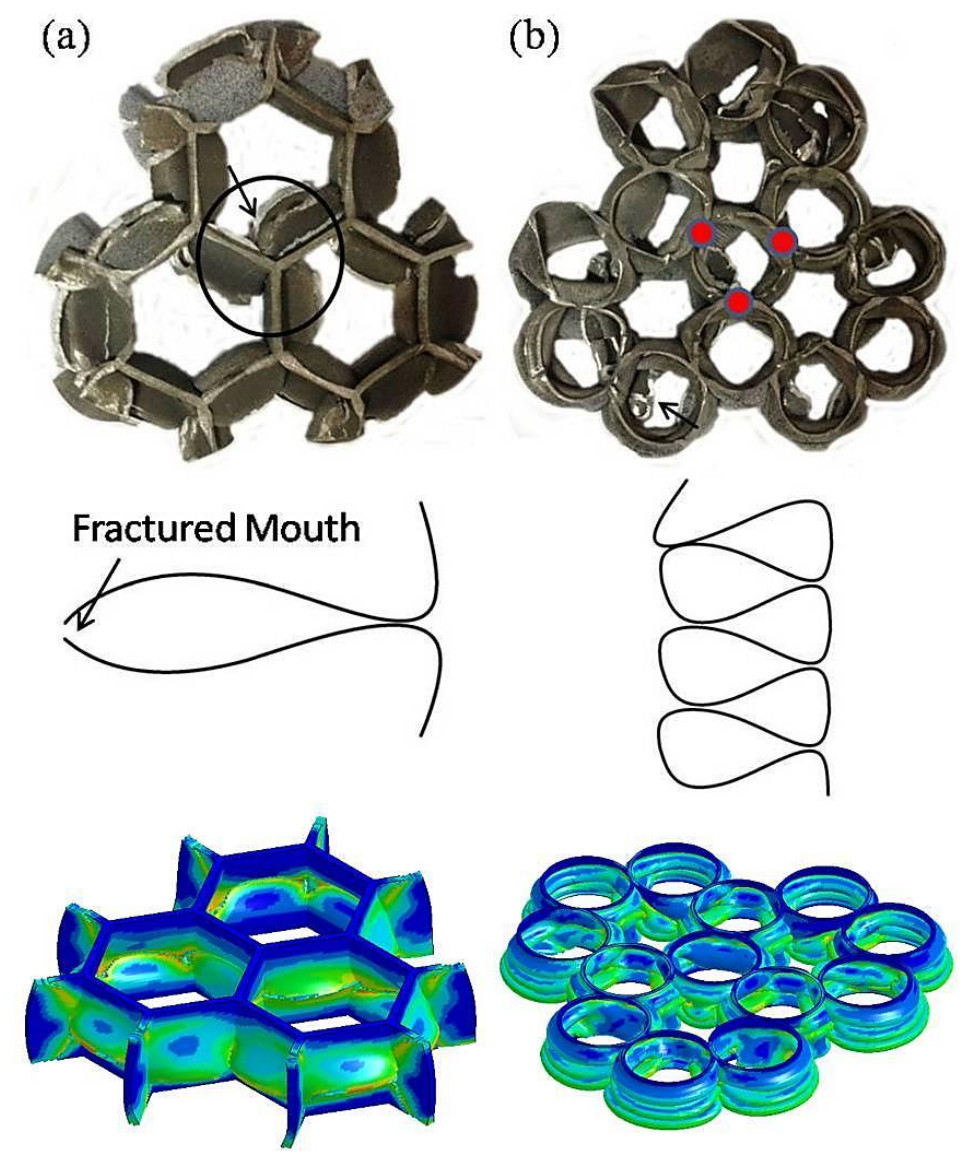

Figure 9. Collapse modes of the (a) sample 1, and (b) sample 5. Simulations show the contour of plastic strain, and a good agreement in the collapse mechanism with experimental results.
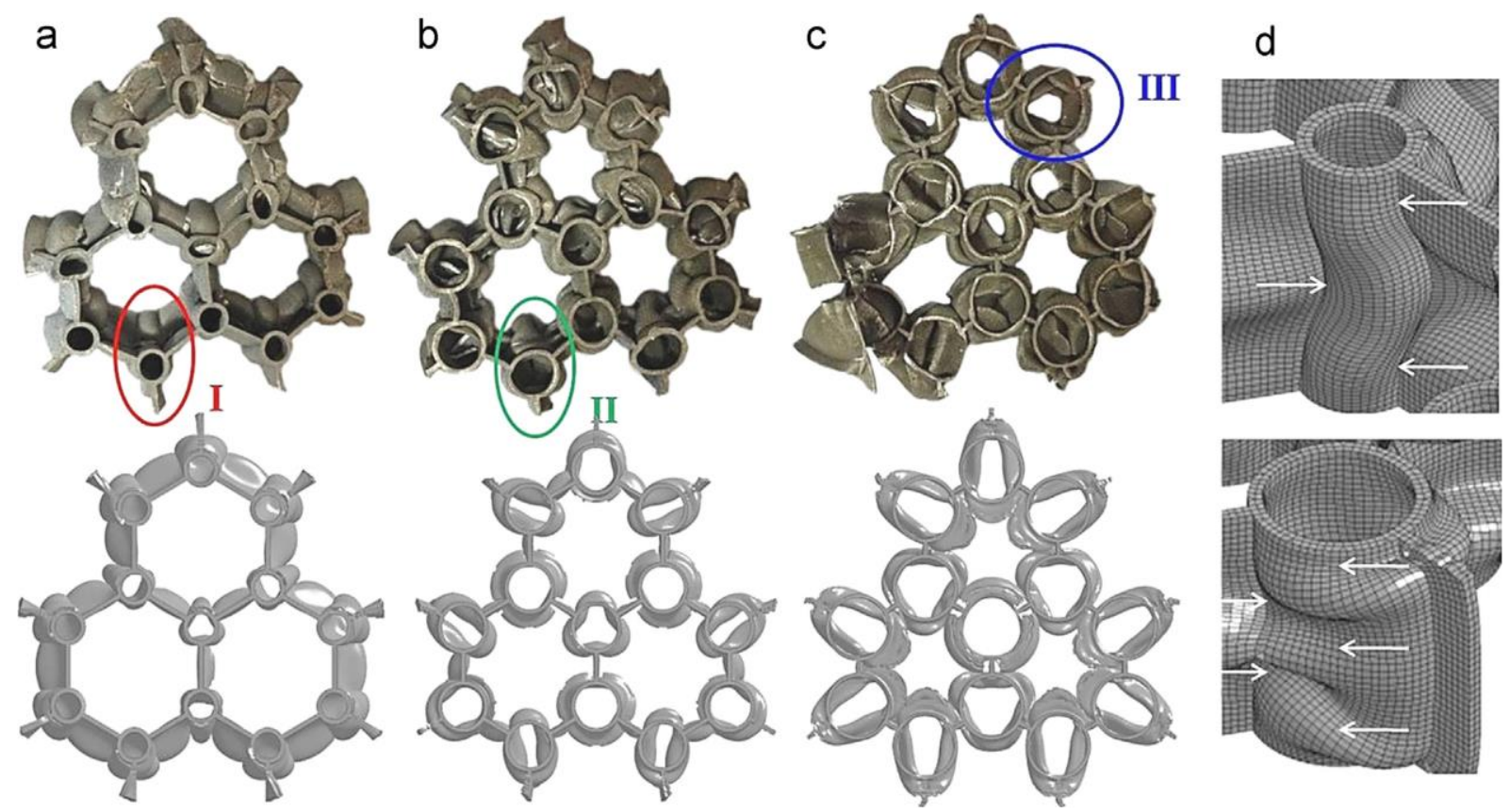

Figure 10. Experimental and simulated collapse modes of the out-of-plane loaded honeycombs with (a) $r / l=0.2$, (b) $r / l=0.3$, (c) $r / l=0.4$ and (d) collapse mechanisms of the cylindrical shellplate joints observed in the simulations, with detail of wall folding. 